\title{
Cashew Nut Positioning during Stone Tool Use by Wild Bearded Capuchin Monkeys (Sapajus libidinosus)
}

\author{
Tiago Falótico ${ }^{\mathrm{a}, \mathrm{b}}$, Lydia V. Luncz ${ }^{\mathrm{b}}$, Magdalena S. Svensson ${ }^{\mathrm{b}, \mathrm{c}}$, Michael Haslam ${ }^{\mathrm{b}}$ \\ ${ }^{a}$ Institute of Psychology, University of São Paulo, São Paulo, Brazil \\ ${ }^{b}$ School of Archaeology, University of Oxford \\ ${ }^{c}$ Department of Social Sciences, Oxford Brookes University, Oxford, UK
}

\begin{abstract}
Wild capuchin monkeys (Sapajus libidinosus) at Serra da Capivara National Park, Brazil, regularly use stone tools to break open cashew nuts (Anacardium spp.). Here we examine 2 approaches used by the capuchins to position the kidney-shaped cashew nuts on an anvil before striking with a stone tool. Lateral positioning involves placing the nut on its flatter, more stable side, therefore requiring less attention from the monkey during placement. However, the less stable and never previously described arched position, in which the nut is balanced with its curved side uppermost, requires less force to crack the outer shell. We observed cashew nut cracking in a field experimental setting. Only 6 of 20 adults, of both sexes, were observed to deliberately place cashew nuts in an arched position, which may indicate that the technique requires time and experience to learn. We also found that use of the arched position with dry nuts, but not fresh, required, in $63 \%$ of the time, an initial processing to remove one of the cashew nut lobes, creating a more stable base for the arch. This relatively rare behaviour appears to have a complex ontogeny, but further studies are required to establish the extent to which social learning is involved.
\end{abstract}

Keywords Stone tool use $\cdot$ Capuchin monkey $\cdot$ Serra da Capivara National Park $\cdot$ Nutcracking $\cdot$ Behavioural plasticity $\cdot$ Cashew nuts

\section{INTRODUCTION}

Percussive stone tool use is rare in non-human primates and is habitually seen in only a few primate species. Chimpanzees in West Africa (Pan troglodytes verus) use percussive wooden 
and stone tools to crack open nuts [Boesch and Boesch, 1983; Koops et al., 2010; Sirianni et al., 2015]; Burmese long-tailed macaques (Macaca fascicularis aurea) use stones to process shellfish, nuts and other prey [Malaivijitnond et al., 2007; Gumert and Malaivijitnond, 2012], and capuchin monkeys ( Sapajus spp.) use percussive stone tools to process palm nuts [Fragaszy et al., 2004; Ottoni and Izar, 2008; Spagnoletti et al., 2011], cashew nuts [Sirianni and Visalberghi, 2013; Falótico and Ottoni, 2016; Visalberghi et al., 2016], and to access hidden resources [Mannu and Ottoni, 2009]. T he cashew tree (Anacardium spp.) is native to Brazil but cultivated in many tropical areas worldwide [Clay, 2013]. The cashew nut is the true fruit of the plant, containing a reproductive seed, which is attached to the perishable pseudofruit [Sirianni and Visalberghi, 2013]. The nut kernel is attractive to monkeys as it is an important source of carbohydrates, lipids and amino acids [Gallina-Toschi et al., 1993], but the shell of cashew nuts contains a phenolic resin, which can cause severe mucosa and skin reactions upon contact [Sirianni and Visalberghi, 2013]. Two well-studied wild populations of bearded capuchin monkeys (Sapajus libidinosus), located approximately $330 \mathrm{~km}$ apart in north-east Brazil, have been found to differ in their approach to cashew nut processing. In Fazenda Boa Vista, capuchins process fresh cashew nuts by rubbing them on an abrasive surface, but use stone tools to crack open dry cashews [Visalberghi et al., 2016]. Conversely, capuchins from Serra da Capivara National Park (SCNP) use stone tools to open both fresh and dry nuts [Falótico and Ottoni, 2016]. There are currently no known ecological explanations for the difference in processing techniques between the 2 sites, although we know that this behaviour has existed for several hundred years at SCNP [Haslam et al., 2016]. Moreover, capuchin monkeys in SCNP have been found to adapt the weight of the tool according to the ripeness stage of the cashew nut, which suggests an understanding of the physical properties of the target nut [Luncz et al., 2016]. One of the most complex skills that young capuchins need to become proficient at nut-cracking is to understand the relationship between 2 movable objects (nut and hammer). As part of this process, they also need to learn how to position the nut on an anvil before they strike [Resende et al., 2008; Fragaszy et al., 2013]. Even for a rounded or elliptical resource, such as hard palm nuts, the position of the nut on the anvil is not random for proficient capuchins [Fragaszy et al., 2013]. Capuchins gain information on how to most efficiently position the palm nuts by knocking them on the anvil prior to positioning and assessing the stability of the placed nut prior to striking [Fragaszy et al., 2013]. Here we report observations of capuchins using 2 methods of positioning cashew nuts on an anvil before processing. The first method involves placing the kidneyshaped nut on its flatter side, which we term lateral positioning. The second method appears more complex, and involves balancing the cashew on 
the anvil in such a way that the arched surface of the nut is upright (Fig. 1) . Arched positioning of cashews has been experimentally shown to require less force to break the nut shell [Ogunsina and Bamgboye, 2013], because of tension cracks that open in the lower, concave portion. This raises the possibility that arched positioning may be a more efficient method for capuchin cashew processing than lateral striking. We hypothesized that use of the arched nut position requires greater motor coordination and skill, because of its inherent lower stability on an anvil. We therefore predicted that this behaviour would be expressed more frequently in adults, who have developed such skills over time, rather than juveniles.

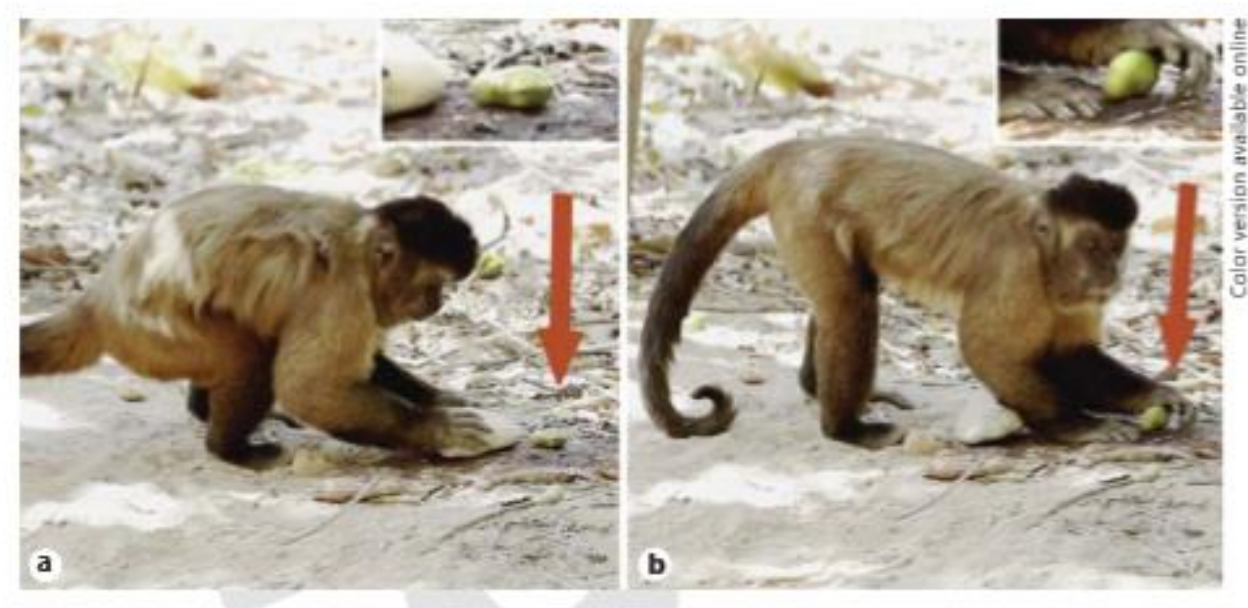

Flg. 1. Capuchin positioning of cashew nuts prior to opening them with a stone tool, SCNP: lateral (a) and arched (b) positions. Insets show the nut position in greater detail.

\section{METHODS}

In September 2013 and May 2014, we carried out tool selection experiments on cashew nut processing in a single group of wild bearded capuchins at SCNP. Each experimental series ran for 2 weeks. The subjects were the Pedra Furada group, fully habituated capuchins with 34-35 individuals that inhabited the south-east border of $\operatorname{SCNP}\left(8^{\circ} 50^{\prime} \mathrm{S}, 42^{\circ} 33^{\prime} \mathrm{W}\right)$. SCNP is situated in Piauí in north-eastern Brazil, at an altitude of 320-600 $\mathrm{m}$ above sea level. The climate in the area is highly seasonal and semi-arid, and the vegetation consists of dry thorn bush. For the experiments, we presented capuchins with a low, flat, sandstone anvil and 5 quartzite stones nearby. The stones weighed 50,100, 200, 300, and $400 \mathrm{~g}$ ( $\pm 10 \%$ in each category) and were collected from around the experimental area. Cashew nuts were sourced from a local commercial cashew farm, and grouped into 2 ripeness stages of dry (later ripening stages, more brittle, usually grey to brown in colour) and fresh nuts (early stage of fruit ripening, bright 
green in colour with an underdeveloped pseudo fruit). The dry and fresh nuts were selected from the extremes of the continuous ripeness stages. Because of cashew availability and time constraints, we provided capuchins with dry cashew nuts during the 2013 study, and fresh cashew nuts in 2014. For further details on the experimental methods, see Luncz et al. [2016]. Experimental trials started when a capuchin approached the experimental site and secured the cashew nut. We then filmed the individual until it left the site. A "bout" was defined as a sequence of positioning and then striking the nut with a stone tool until the nut was opened and consumed, or until a new bout started with a repositioning of the nut. Each of the trials was filmed using an HD camcorder, from an average distance of $5 \mathrm{~m}$ from the anvil. The researcher filming the trials narrated the trial number, identity, sex and age of the monkey, as well as the stone used to crack the nut. We recorded the number of strikes needed to successfully open each nut, and capuchin positioning of the nuts (lateral or arched) before striking (Fig. 1).

\section{RESULTS}

We sampled 30 individuals ( 9 adult males, 11 adult females, 8 juvenile males and 2 juvenile females), totalling 513 trials and 1,041 bouts. Capuchins used a lateral positioning of the nut during the large majority of the bouts $(95.8 \%)$, but 6 adult mon keys were observed to also use the arched position (online suppl. videos 1 and 2; for all online suppl. material, see www.karger.com/doi/10.1159/000459621). Only adult monkeys used the arched position, with each individual employing this positioning style in $2-33 \%$ of their bouts (Table 1). Juveniles accounted for $6 \%$ of the bouts, having less access to the experimental site due to monopolization by adults. The arched position was observed for processing of both fresh and dry nuts (Table 2$)$. The monkeys averaged 2 bouts per trial $(\mathrm{SD}=1.4)$, with the majority of uses $(59 \%)$ of the arched technique registered on the first bout of the trial. The average number of strikes per bout was $2.8(\mathrm{SD}=2.1)$; the average for lateral positioning was $2.8(\mathrm{SD}=2.2)$ and for arched positioning 1.6 strikes $(\mathrm{SD}=0.9)$. An additional step before adjusting the nut in the arched positioning regularly occurred when capuchins processed the dry nuts. In $63 \%$ of the bouts where capuchins used arched positioning, they removed part of 1 cashew lobe by biting it off, before positioning the nut (Table 2; online suppl. video 2). Before positioning dry nuts in the lateral position, the capuchins only bit the nut in $12 \%$ of the time. Owing to our sample size, we were not able to test for significant differences in the number of strikes required to open arched or laterally positioned nuts. 
Table 1. Frequencies of bouts for individuals that used the arched position for cashew nut processing, SCNP

\begin{tabular}{lllll}
\hline Individual & Sex & Age & Bouts, $n$ & Arched position, $n$ \\
\hline Benne & $\mathrm{F}$ & adult & 52 & $17(32.7 \%)$ \\
Gorda & $\mathrm{F}$ & adult & 52 & $1(1.9 \%)$ \\
Ninfa & $\mathrm{F}$ & adult & 65 & $1(1.5 \%)$ \\
Roger & $\mathrm{M}$ & adult & 80 & $3(3.7 \%)$ \\
Torto & $\mathrm{M}$ & adult & 58 & $2(3.4 \%)$ \\
Zandor & $\mathrm{M}$ & adult & 122 & $20(16.4 \%)$ \\
\hline Total & & & 429 & $44(10.2 \%)$ \\
\hline
\end{tabular}

Table 2. Frequency of bouts by position and cashew nut stage, and frequency of lobe removal before using the arched position, SCNP

\begin{tabular}{llll}
\hline & Lateral position & Arched position & $\begin{array}{l}\text { Lobe removal before } \\
\text { arched position }\end{array}$ \\
\hline Fresh nuts & $441(96.9 \%)$ & $14(3.1 \%)$ & $0(0 \%)$ \\
Dry nuts & $556(94.9 \%)$ & $30(5.1 \%)$ & $19(63 \%)$ \\
\hline
\end{tabular}

\section{DISCUSSION}

The use of stone tools to process cashew nuts and other resources is widespread in the SCNP capuchin population [Mannu and Ottoni, 2009; Falótico and Ottoni, 2016], but even though individuals use similar processing techniques, there is variance in the behaviour. Our results show that when capuchins at SCNP crack cashew nuts with stone tools they typically position the nut flat on the hard anvil surface. However, $30 \%$ of the adult capuchins position the nut in an arched position (Fig. 1 b) at least some of the time. Although there are studies on the positioning of the more symmetrical palm nuts by capuchin monkeys [Fragaszy et al., 2013], this study is the first that reports such variation for cashew nut processing in wild capuchins. Learning to crack nuts is a time-consuming process. West African chimpanzees (Pan troglodytes verus) take at least 5 years to master this behaviour for Coula nuts [Boesch and Boesch, 1984], and the use of the hammers appears to be the most difficult tool-using skill that these apes acquire. In the case of the capuchin monkeys, in order to proficiently crack encased fruits with stone tools, correct positioning of the target nut is the most difficult behaviour to learn [Resende et al., 2008]. For symmetrical elliptical or rounded fruits, like most palm nuts and seeds, positioning is dependent on the selection of a suitable anvil surface that prevents the target food from rolling prior to a strike [Fragaszy et al., 2013]. However, for cashew nuts, which have an arched shape, positioning the nut in any orientation other than laterally is more 
challenging. In particular, the use of the more energy-efficient arched position appears to require skills that only adult capuchins have developed. The arched position requires the capuchins to take great care to balance the nut without it immediately falling over into the lateral position (see online suppl. videos). Less force is necessary to break open the nut shell in the arched position [Ogunsina and Bamgboye, 2013]. In general, we expect that behavioural modifications, including tool use behaviour, would be repeated more often if the outcome is more productive (e.g., higher energy returns or lower energy costs). If the capuchins that employ the arched striking strategy are following this expectation, then the absence of individuals that used this position as a primary choice could reflect the fact that its efficiency is counteracted by increased attention and effort needed to place the nut in a less stable position. Only adults used the arched variant, which may indicate that the more complex manipulation involved in positioning the nut in a less stable position requires the development of adult-level skills, although we cannot rule out a sampling bias. We know that cashew nut processing with stone tools is present in at least 1 other population of capuchins, at Fazenda Boa Vista [Visalberghi et al., 2016], but we do not currently know whether this variant of positioning is present in this or other capuchin populations that use stone tools to process cashew nuts. Another factor not analysed here is whether different types of anvil materials or inclinations could elicit different frequencies of positioning styles. If this behaviour is difficult to discover individually (or if the benefits are balanced or outweighed by the costs), it is likely to remain restricted to some individuals or groups. However, if it is easily discovered or significantly beneficial, then we might expect to see the arched position occurring independently among groups and sites. We anticipate that our initial observations and experiments regarding this behavioural variant at SCNP will facilitate the search for similar observations at other sites across the capuchin range.

\section{ACKNOWLEDGEMENTS}

Funding was received from a European Research Council grant to M.H. (No. 283959) and from São Paulo Research Foundation to T.F. (2013/05219-0, 2014/18364-1). The research was previously approved by IBAMA/ICMBio (authorization 37615-1) and adhered to the ASAB/ ABS Guidelines for the Use of Animals in Research. We thank FUMDHAM, Niède Guidon, Eduardo B. Ottoni, Alejandra Pascual-Garrido, Clara de Souza Corat, George Reinaldo, and Hannah Mosley. 


\section{DISCLOSURE STATEMENT}

The authors declare no competing interests and no conflicts of interests.

\section{REFERENCES}

Boesch C, Boesch H (1983). Optimisation of nut-cracking with natural hammers by wild chimpanzees. Behaviour 83: 265-286.

Boesch C, Boesch H (1984). Possible causes of sex differences in the use of natural hammers by wild chimpanzees. Journal of Human Evolution 13: 415-440.

Clay JW (2013). World Agriculture and the Environment. Washington, Island Press.

De Resende BD, Ottoni EB, Fragaszy DM (2008). Ontogeny of manipulative behavior and nutcracking in young tufted capuchin monkeys (Cebus apella): a perception-action perspective. Developmental Science 11: 828-840.

Falótico T, Ottoni EB (2016). The manifold use of pounding stone tools by wild capuchin monkeys of Serra da Capivara National Park, Brazil. Behaviour 153: 421-442.

Fragaszy DM, Izar P, Visalberghi E, Ottoni EB, de Oliveira MG (2004). Wild capuchin monkeys (Cebus libidinosus) use anvils and stone pounding tools. American Journal of Primatology 64: 359-366.

Fragaszy DM, Liu Q, Wright BW, Allen A, Brown CW, Visalberghi E (2013). Wild bearded capuchin monkeys (Sapajus libidinosus) strategically place nuts in a stable position during nutcracking. PLoS One 8: e56182.

Gallina-Toschi T, Caboni MF, Penazzi G, Lercker G, Capella P (1993). A study on cashew nut oil composition. Journal of the American Oil Chemists' Society 70: 1017-1020.

Gumert MD, Malaivijitnond S (2012). Marine prey processed with stone tools by Burmese long-tailed macaques (Macaca fascicularis aurea) in intertidal habitats. American Journal of Physical Anthropology 149: 447-457.

Haslam M, Luncz LV, Staff RA, Bradshaw F, Ottoni EB, Falótico T (2016). Pre-Columbian monkey tools. Current Biology 26: R521-R522. 
Koops K, McGrew WC, Matsuzawa T (2010). Do chimpanzees (Pan troglodytes) use cleavers and anvils to fracture Treculia africana fruits? Preliminary data on a new form of percussive technology. Primates 51: 175-178.

Luncz LV, Falótico T, Pascual-Garrido A, Corat C, Mosley H, Haslam M (2016). Wild capuchin monkeys adjust stone tools according to changing nut properties. Scientific Reports 6: 33089 .

Malaivijitnond S, Lekprayoon C, Tandavanittj N, Panha S, Cheewatham C, Hamada Y (2007). Stone-tool usage by Thai long-tailed macaques (Macaca fascicularis). American Journal of Primatology 69: 227-233.

Mannu M, Ottoni EB (2009). The enhanced tool-kit of two groups of wild bearded capuchin monkeys in the Caatinga: tool making, associative use, and secondary tools. American Journal of Primatology 71: 242-251.

Ogunsina BS, Bamgboye AI (2013). Fracture resistance of cashew nuts as influenced by preshelling treatment. International Journal of Food Properties 16: 1452-1459.

Ottoni EB, Izar P (2008). Capuchin monkey tool use: overview and implications. Evolutionary Anthropology 17: 171-178.

Sirianni G, Visalberghi E (2013). Wild bearded capuchins process cashew nuts without contacting caustic compounds. American Journal of Primatology 75: 387-393.

Sirianni G, Mundry R, Boesch C (2015). When to choose which tool: multidimensional and conditional selection of nut-cracking hammers in wild chimpanzees. Animal Behaviour 100: $152-165$.

Spagnoletti N, Visalberghi E, Ottoni EB, Izar P, Fragaszy DM (2011). Stone tool use by adult wild bearded capuchin monkeys (Cebus libidinosus). Frequency, efficiency and tool selectivity. Journal of Human Evolution 61: 97-107.

Visalberghi E, Albani A, Ventricelli M, Izar P, Schino G, Fragazsy D (2016). Factors affecting cashew processing by wild bearded capuchin monkeys (Sapajus libidinosus, Kerr 1792). American Journal of Primatology 78: 799-815. 